\title{
Gravuras em metal à maneira de Michelangelo durante o Cinquencento *
}

A gravura em metal, mais precisamente a técnica do buril, começou na Itália por volta de 1450 com a utilização do "niello"1 procedente das oficinas dos ourives Florentinos. Depois de uma década, a gravura propriamente dita tornou-se uma realidade, pois a prata fundida foi substituída por chapas de metal, de custo mais baixo, e foram introduzidas prensas provenientes da Alemanha essenciais para a impressão das imagens. É importante notar a procedência social dos gravadores do século $\mathrm{XV}$. Enquanto os gravadores em madeira geralmente eram de classes mais baixas e artesãos, os gravadores em metal provinham de ourivesarias e procuravam situar-se próximo aos artistas da época.

Pode-se identificar, no início da Renascença, dois pintores que utilizaram a técnica do buril com grande êxito: Antonio Pollaiuolo e Andrea Mantegna. É de autoria de Pollaiuolo a gravura "A batalha dos homens nus", feita por volta de 1470 e considerada uma das obras primas em gravura do início da Renascença.

Na primeira década do século XVI a gravura a buril, também conhecida como talho doce, avançou enormemente desenvolvendo-se tanto tecnicamente como estilisticamente em diferentes direções. Muitas das gravuras eram essencialmente reprodutivas. A proposta destes trabalhos era exaltar as obras originais das quais eram procedentes e disseminar as novas idéias artísticas em grande parte da Europa. É importante salientar as vantagens das gravuras sobre as pinturas e afrescos no que diz respeito à

* Trabalho realizado no curso de Mestrado em Artes Plásticas no Pratt Institute, New York, USA, 1990. 
divulgação de idéias, devido à facilidade de transporte, por serem em geral de dimensões reduzidas e sobre papel.

As gravuras eram freqüentemente baseadas em pinturas e afrescos, bem como em desenhos de artistas. Seu objetivo era reproduzir o desenho, isto é, a composição básica, e não reproduzir as texturas pintadas do original. As gravuras possuiam o estilo e a técnica de cada gravador e não necessariamente duplicavam o aspecto e a expressão de seu modelo original. Isto será o objetivo dos gravadores dos séculos XVIII e XIX.

No século XVI, Michelangelo era a figura dominante em Roma e seu trabalho era estudado e copiado continuamente por gravadores. Embora havendo em cada imagem copiada a leitura e interpretação do gravador, a gravura acabava sendo um simulacro de Michelangelo. Uma vez que a burguesia emergente, desenvolvendo o princípio da apropriação privada, começava a levar para seus domínios os bens culturais públicos, a aquisição de uma gravura permitia ao comprador possuir simbolicamente um "Michelangelo" e, ao mesmo tempo, uma imagem religiosa.

Entre os gravadores que copiaram Michelangelo no século XVI, os mais conhecidos são Marcantonio Raimondi, Giorgio Ghisi e Agostino Carracci. Embora todos tenham trabalhado durante o Cinquecento, os três gravadores apresentam características diversas, que serão aqui analisadas.

Marcantonio Raimondi (1480-1534) foi o mais importante e influente gravador italiano do século XVI. Marcantonio obteve seu treinamento no atelier de Francesco Francia onde pode formar seu estilo inicial. Em 1506 ele foi a Veneza e copiou algumas gravuras de Dúrer, as quais fez passar por originais. De Veneza foi a Florença e copiou a "Batalha de Cascina" de Michelangelo. A gravura "Os escaladores", baseada neste trabalho, é um documento importante porque é um dos poucos registros que restam deste trabalho de Michelangelo. Sua primeira gravura desta série foi executada em 1508 e possui apenas uma figura de costas. Em 1510 ele executou outra gravura, incorporando três figuras. Também é importante notar a seleção feita por Marcantonio, na qual aparecem três figuras em poses distintas, e o rio do qual os homens estão emergindo é eliminado, reformulando assim a imagem original.

"A expulsão de Adão e Eva do paraíso" (fig. 1) foi provavelmente executada por volta de 1512. Marcantonio utiliza apenas metade da cena da expulsão do paraíso feita por Michelangelo e também faz as figuras mais magras e com a expressão facial exagerada. Também acrescenta uma 
pequena paisagem, a qual indica seu conhecimento de Dürer. O toco da árvore, uma imagem que Michelangelo usou na "Tentação", é aqui aumentado, fazendo um trabalho de gravação independente da imagem original.

Ele também copiou Rafael, porém com seu consentimento. Rafael foi o primeiro dos grande pintores que percebeu o valor de colocar um gravador de primeira linha inteiramente a seu serviço, no que diz respeito à divulgação de seu trabalho através de gravuras. Além dos afrescos, Rafael fornecia desenhos para serem usados como base para as gravuras de Marcantonio.

Conseqüentemente, o grande número de gravuras que foram produzidas por Marcantonio e sua oficina disseminaram o estilo da alta Renascença, tendo Michelangelo como figura central, em grande parte da Europa. Entretanto, o maior número de gravuras conhecidas baseadas em Michelangelo é proveniente do gravador Giorgio Ghisi (1520-82), e não de Marcantonio.

Giorgio Ghisi foi gravador reprodutor, isto é, seu trabalho reproduziu essencialmente desenhos feitos por outro. Portanto, o talento de Ghisi não recai em invenção e sim na transcrição de imagens para a linguagem da gravura. Ele reproduziu trabalhos de seus contemporâneos, principalmente artistas italianos. Os temas de suas gravuras também mostravam, em amplos termos, o gosto da época. Ele trabalhou motivos religiosos, mitológicos, históricos e retratos, etc.

Entre 1540 e 1550 reproduziu, em uma grande gravura medindo 120 $\mathrm{cm}$ por $120 \mathrm{~cm}$, (fig. 2), em 10 placas separadas, o mais famoso trabalho daquela época, o "Juízo Final" de Michelangelo, pintado na parede do altar da Capela Sistina no Vaticano. Este trabalho não foi a primeira gravura baseada no famoso afresco pintado entre 1532 e 1541; uma gravura com também 10 seções, foi feita antes do fim do século XVI, mas a de Ghisi supera todas porque é a mais próxima ao afresco de Michelangelo, principalmente com relação à escala das figuras. A gravura de Ghisi talvez tenha sido baseada no desenho original de Michelangelo. Prova disso é a posição que se encontra São Brás. Depois da decisão do Concílio de Trento em 1564 o afresco da Capela Sistina foi alterado, —a posição da cabeça de São Brás, figura imediatamente acima de Santa Catarina, à direita, no grupo dos abençoados, foi mudada, fazendo-o olhar para Cristo. A posição original foi considerada obscena pela Igreja Católica. Na gravura de Ghisi, a figura olha para baixo em direção a Santa Catarina, conforme o trabalho original, como salienta Suzanne Boorsch (1985). 
No início de 1570, Ghisi criou uma grande série de Profetas e Sibilas, a partir do trabalho de Michelangelo no teto da Capela Sistina. Esta série de gravuras reproduz com grande fidelidade 6 dos 12 profetas. A profundidade de tons, fortemente enfatizada, é obtida pelo uso de pontos entre as linhas.

O trabalho de Ghisi é de alta qualidade técnica, mas provavelmente ele não foi considerado um artista criativo. Ele não era um gravador experimental. Os diferentes estados das gravuras de Ghisi não refletem, como as de Rembrandt, um esforço para atingir variados efeitos estéticos. Em muitos casos, a única diferença entre os estados é a adição do nome do editor.

Ghisi também foi influenciado por Marcantonio, mas pode ser considerado a maior influência na gravura italiana depois deste e antes de Agostino Carracci.

Em 1564 o Concilio de Trento, o qual tinha sido convocado para combater os efeitos da Reforma Protestante, completou seu trabalho. Entre seus decretos estavam uma série de regulamentaç̃es no que diz respeito à arte em igrejas como objetos de veneração. Seus resultados tornaram-se aparentes nos últimos anos do século XVI e no começo do século XVII. Uma nova ênfase foi dada à crescente produção de trabalhos religiosos, bem como à criação de fortes e veementes representações da fé religiosa.

Durante este período, Agostino Carracci (1557-1602) trabalhou como gravador, reproduzindo notáveis trabalhos de arte em gravura que divulgavam as pinturas e afrescos dos quais procediam, à maneira como são agora publicados fotograficamente. Suas gravuras mais conhecidas são "Pietà" e "Mater dolorosa", a partir das duas obras de Michelangelo. Há várias teorias a respeito da origem da "Pietà". Não é claro se Agostino foi a Roma para ver a escultura a fim de reproduzí-la em gravura, ou se ele obteve uma cópia em papel (desenho ou gravura), uma vez que a Pietà de Michelangelo foi muito reproduzida em gravuras e desenhos por vários artistas. Também não é claro a origem da gravura "Mater dolorosa" (ou Pietà para Vitória Colona) (fig. 3). Provavelmente, sua origem possa ser a gravura de Giulio Bonasone de 1546 e não o desenho de Michelangelo. Agostino mudou o formato da cruz e acrescentou no fundo paisagem com vilarejo; mas a colina onde acontece a ação é similar em ambas as gravuras. O sombreado e a hachura na gravura de Carracci são muito próximas aos de Bonasone. 
É importante mais uma vez salientar que gravadores reprodutores, trabalhando a partir de uma mesma imagem, podem produzir gravuras diferentes entre si, em efeitos e valores estéticos. A natureza destas reproduções possui características muito diversas das reproduções feitas através da fotografia no século XX. Enquanto que a fotografia, quando vista como meio reprodutivo, procura aproximar-se do original utilizando-se de meios mecânicos e obtendo excelentes resultados, a gravura, também quando vista como meio reprodutivo, não possui esta fidelidade ao original, pois seu processo é essencialmente manual, possibilitando interpretações diversas por parte dos gravadores.

Entre os gravadores que trabalharam usando as obras de Michelangelo pode-se também apontar: Nicolas Beatrizet (1515?-60?), Enea Vico (1541-67), Martino Rota (1558-86), Gianbatista Cavalieri (1525-97), Antonio Salamanca (1510-47), Adamo Mantovano (?); todos vazios de expressividade, porém contribuíram para a divulgação da obra de Michelangelo.

Todos os trabalhos aqui mencionados foram executados com a técnica do buril. Este processo de gravação possui relação com a rigidez do século XV e XVI. Apenas poucos artistas trabalharam com o processo de água-forte durante estes séculos. Na água-forte é possível uma espontaneidade de expressão bem maior que no burril, devido à leve resistência do verniz sobre a chapa, proporcionando grande afinidade com o espírito da arte dos séculos seguintes.

A segunda metade do século XVI foi um tempo de enorme crescimento da demanda de gravuras. Elas foram utilizadas em diferentes áreas, solidificando sua posição como meio reprodutivo e de expressão na Europa. Neste século a gravura serviu para a confecção de mapas topográficos do Novo Mundo. Grandes teóricos da Arte, como Vasari, tiveram que se valer de gravuras por falta de originais. A igreja, afetada pelo Protestantismo, usou a gravura religiosa como propaganda de seu credo. A importância quantitativa da cópia de obras de Michelangelo é novamente enfatizada, uma vez que o artista foi figura paradigmática da Renascença, já no período de sua atuação e ainda mais nos anos posteriores, e boa parte de sua obra é centrada na representação de temas religiosos.

A gravura, mesmo considerada como meio reprodutive, teve um importante papel durante o século XVI na disseminação de suas idéias e imagens estéticas. Portanto, a divulgação das obras de Michelangelo através 
de gravuras é dado essencial para o estudo do reconhecimento e apreciação de seu trabalho no século XVI e seguintes.

\section{NOTA}

1) "O Nielo é um procedimento específico de ourivesaria que consiste na gravação com buril sobre um metal nobre e posterior recobrimento dos traços do desenho com uma substância escura (formada pela fusão do cobre, prata, chumbo e enxofre) chamada 'Nigellum'. O resultado final é o desenho em negro sobre uma superfície brilhante. Antes da realização do nielo, os ourives tiravam provas em papel da superfície em relevo, para poder guardá-la como modelo para outros trabalhos". Martins, Carlos, 1981/2. 


\section{BIBLIOGRAFIA}

BOHLIN, Diane de Grazia. Prints and related drawings by Carracci family: a catalogue raisone. Washington: National Gallery of Art. 1979.

BORSCH, Suzanne. The engravings of Giorgio Ghisi. New York: Metropolitan Museum of Art. 1985.

DE TOLNAY, Charles. Michelangelo Buonaroti. Princeton: Princeton University, 1969-71.

HIND, Arthur Mayger. A history of engraving \& etching from the 15th century to the year 1914. New York: Dover. 1963.

MARTINS, Carlos. Introdução ao conhecimento da gravura em metal. Rio de Janeiro: PUC, 1982.

PETRUCCI, Alfredo. Il cinquecento. Roma: C. Bestetti, 1964.

SHOEMAKER, Innis H. The engravings of Marcantonio Raimondi. Lawrence: Spencer Museum of Art. 1981.

VASARI, Giorgio. The lives of the artists. New York: Penguin Books, 1971.

MARIA LUCIA CATTANI - Master of Fine Arts pelo Pratt Institute, New York, USA; Profa. de Gravura do Departamento de Artes Visuais do Instituto de Artes da UFRGS. 


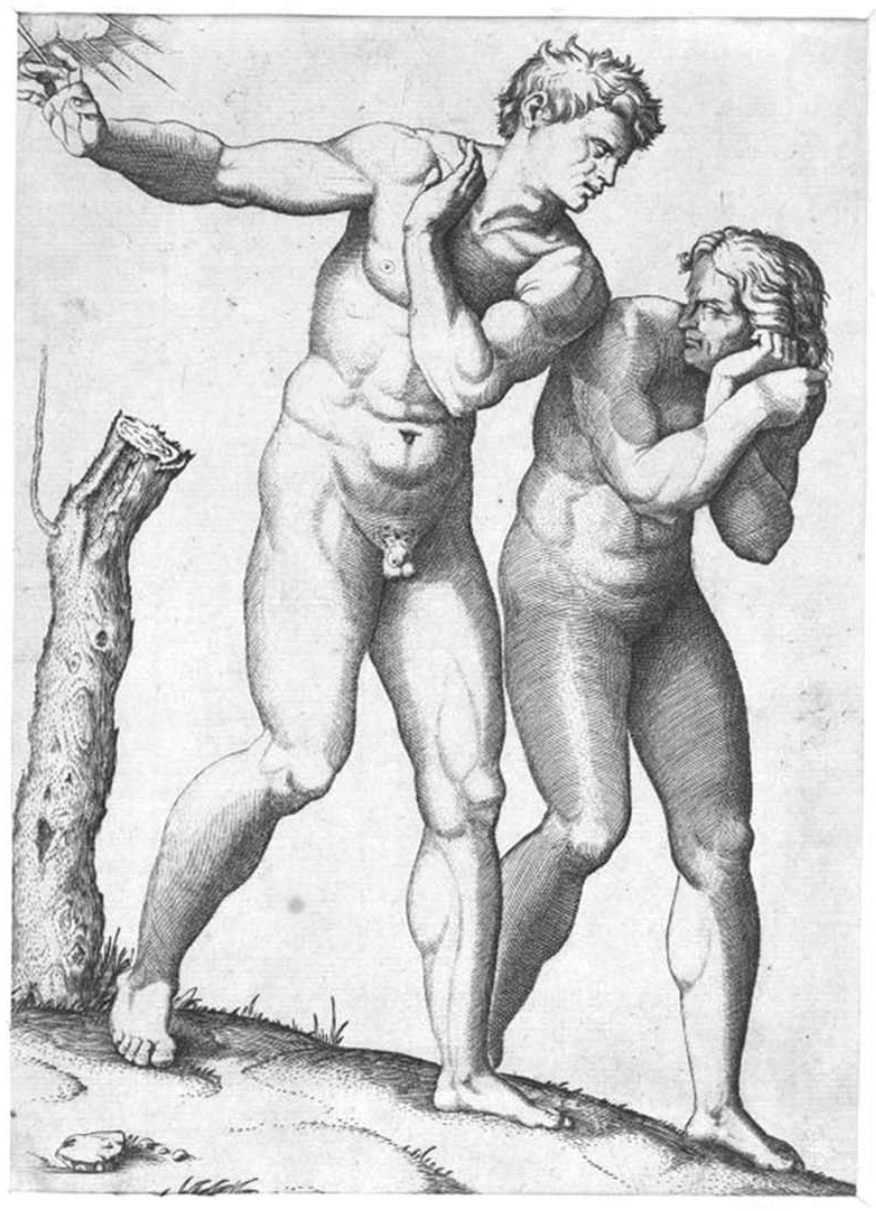

Fig. 1 - Marcantonio Raimondi, A expulsão de Adão e Eva do paraíso, $1512,19,2 \times 12,9 \mathrm{~cm}$. 


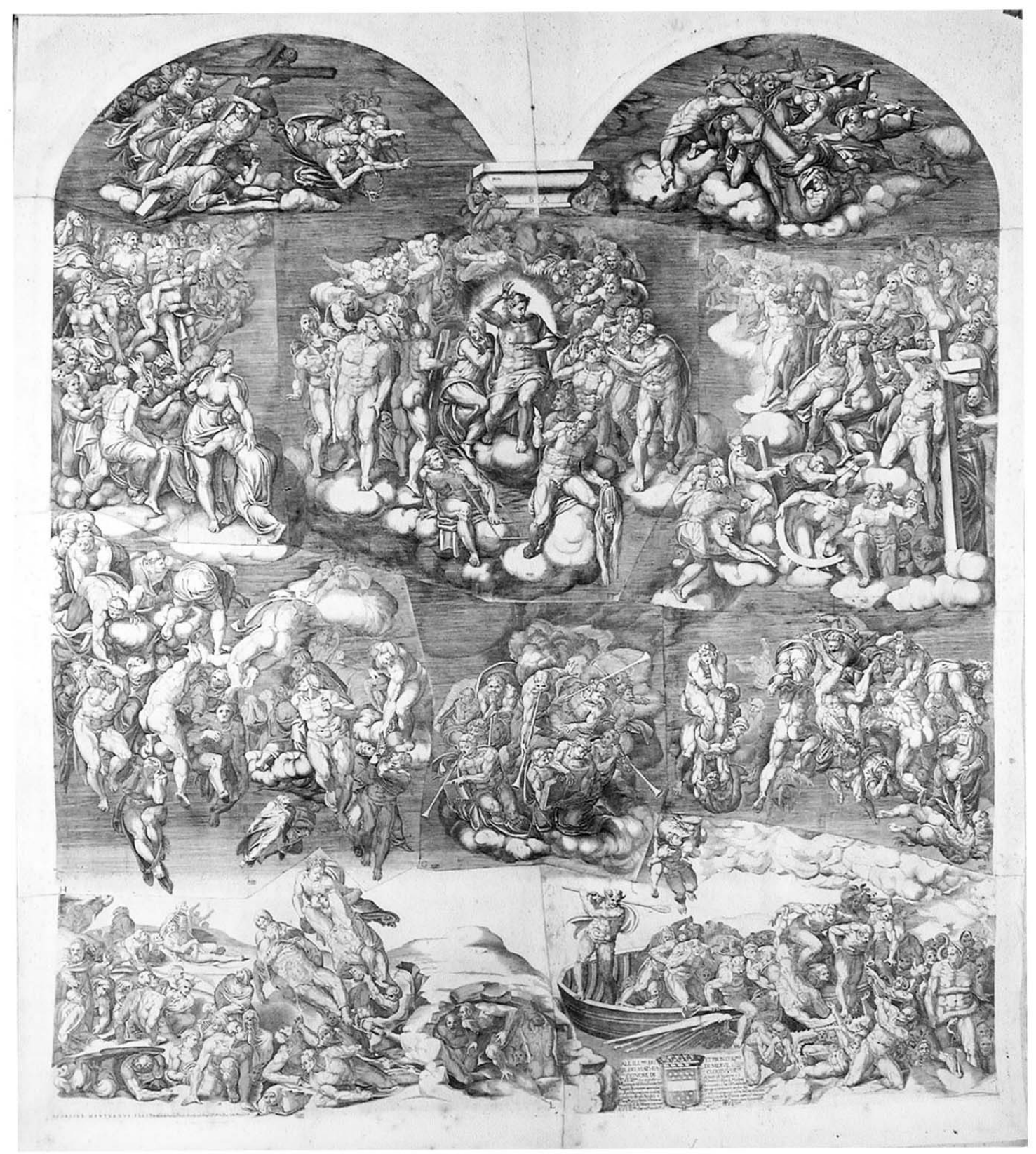

Fig. 2 - Giorgio Ghisi, Juzzo Final, 1540-1550, $120 \times 120 \mathrm{~cm}$. 


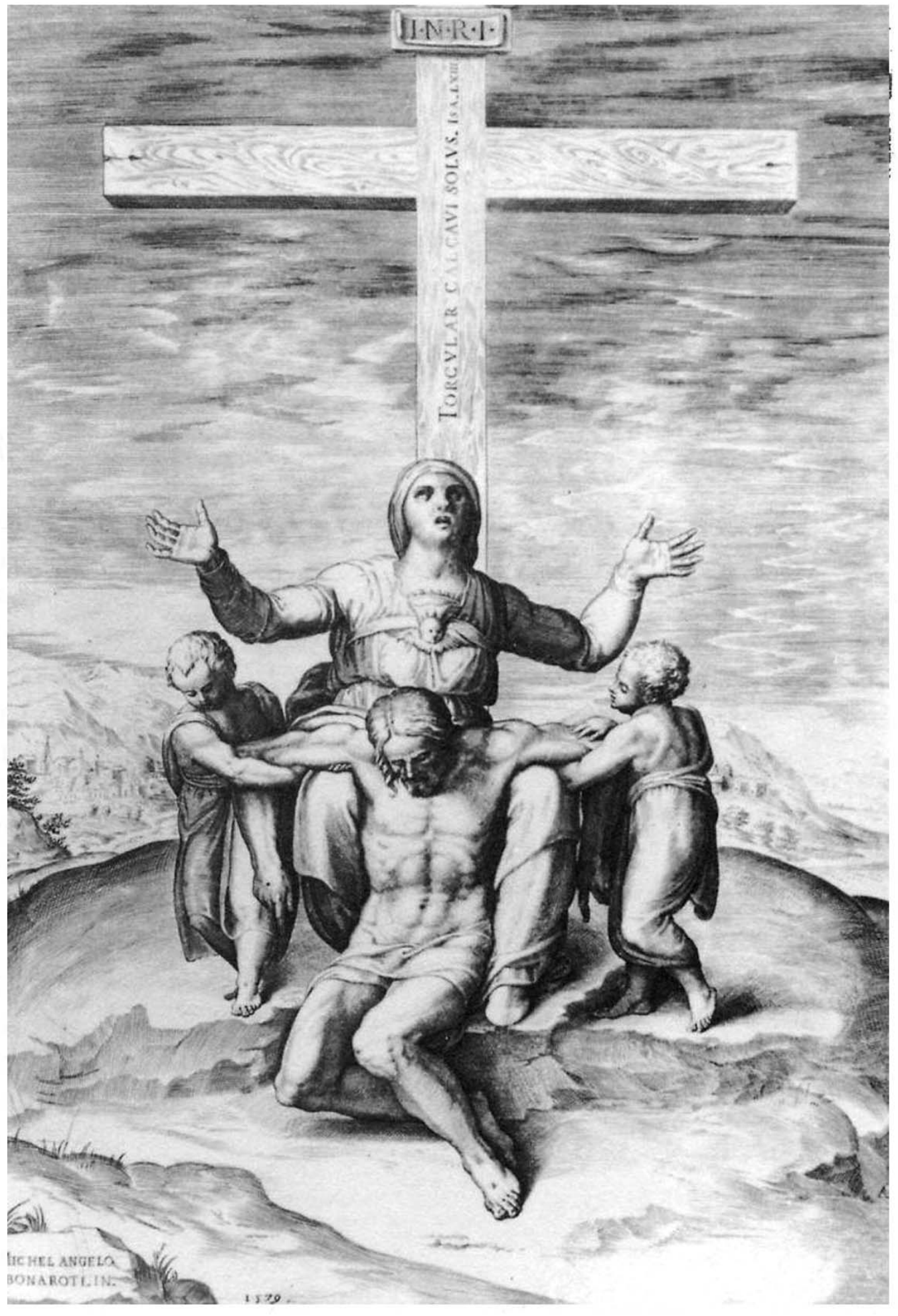

Fig. 3 - Agostino Carracci, Mater dolorosa, 1579,41,1 $\times 28,7 \mathrm{~cm}$. 